\title{
The challenge of primary gastric melanoma: a systematic review
}

\author{
Gregory S Mellotte*,1,3 (D), Diya Sabu², Mary O'Reilly ${ }^{1}$, Ray McDermott ${ }^{2}$, Anthony \\ $\mathrm{O}^{\prime}$ Connor ${ }^{1,3}$ \& Barbara M Ryan ${ }^{1,3}$ \\ ${ }^{1}$ Department of Gastroenterology, Tallaght University Hospital, Dublin, D24 NR04, Ireland \\ ${ }^{2}$ Department of Oncology, Tallaght University Hospital, Dublin, D24 NR04, Ireland \\ ${ }^{3}$ Department of Clinical Medicine, Trinity College Dublin, D02 PN40, Ireland \\ *Author for correspondence: gregmellotte@gmail.com
}

\begin{abstract}
Aim: Primary gastric melanoma is a rare clinical presentation. The purpose of this review was to compare the 1-year survival in patients who underwent surgery with patients who did not receive treatment. Patients \& methods: A systematic search of databases for case reports and case series of primary gastric melanoma was conducted. Results: The mean survival of patients was 22 months. One-year survival was $56.5 \%$ with surgery, rising to $66 \%$ with adjuvant therapy. Mean survival of the surgical group was 21.05 months ( \pm 20.2$)$ versus 4.5 months $( \pm 3.61)$ in the nonsurgical group. Conclusion: Primary gastric melanoma has a poor prognosis but early surgical intervention can have a significant impact on patient outcome. We reviewed the biology and clinical diagnosis of gastrointestinal melanoma and the current management options available.
\end{abstract}

First draft submitted: 19 May 2020; Accepted for publication: 18 August 2020; Published online: 23 November 2020

Keywords: gastric melanoma • gastrointestinal cancer • malignant melanoma • neoplasm • stomach • surgery

Melanoma of the GI tract is a rare cause of gastrointestinal (GI) pathology found at endoscopy. However, cutaneous melanoma has been found to metastasize to the GI tract in up to $60 \%$ of cases. Unfortunately, given the aggressive nature of this cancer frequently the metastases are diagnosed at postmortem [1]. These metastases can become symptomatic and present significant complications in the clinical management of patients with melanoma. Primary melanoma of the GI tract is a much rarer entity. Falling under the term of mucosal melanoma, it constitutes approximately $1.4 \%$ of melanoma [2]. Often presenting with an insidious course and a wide range of appearances at endoscopy, it can be difficult to recognize. Mucosal melanoma presents most frequently in the anorectum with the esophagus being the second most commonly recorded location. It has been reported throughout the GI tract, at times found at more than one site [2].

The picture of GI melanoma is further muddied by the potential of cutaneous melanoma to regress. The pathophysiology of regression is unknown and given the nature of the phenomenon it is extremely difficult to study or observe. This can cause further confusion in the distinction between melanoma of unknown primary and primary mucosal melanoma of the GI tract [3].

We systematically reviewed the literature to assess the 1-year survival of patients with primary gastric melanoma who underwent surgery compared with those who did not receive treatment. We examined the evidence for primary gastric melanoma and discuss the possible mechanism of development, which may help guide the treatment of these tumors that carry a historically poor prognosis.

\section{Patients \& Methods}

This review was performed following the methodology of the Cochrane handbook for systematic reviews [4] and the PRISMA (Preferred Reporting Items for Systematic Reviews and Meta-Analyses) statement [5]. The study is registered on the International Platform of Registered Systematic Review and Meta-analysis Protocols (registration number: INPLASY202070020/DOI: 10.37766/inplasy2020.7.0020). 
A literature search for studies published was conducted using the PubMed database, Google scholar and Europe PMC. The search terms used were 'primary gastric melanoma' OR 'gastric melanoma' OR 'melanoma of the stomach' OR 'gastrointestinal melanoma'. The search results were screened using title, abstract and full text to identify papers discussing primary gastric melanoma. The study selection process is outlined in the PRISMA diagram below (Figure 1).
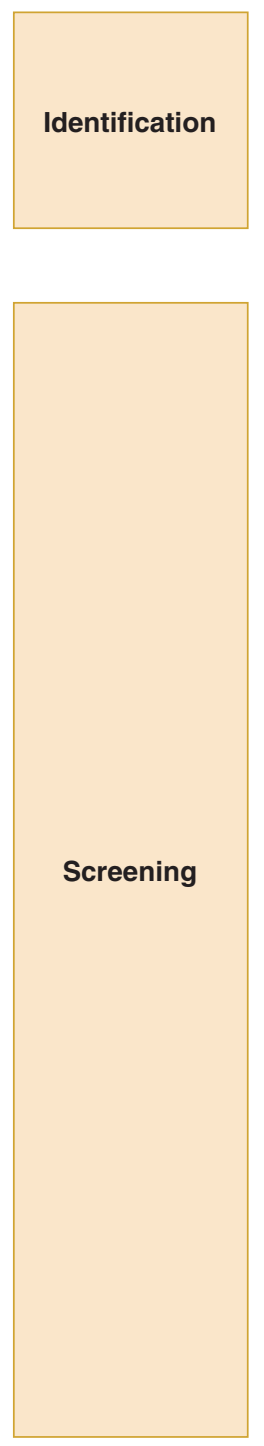

Eligibility

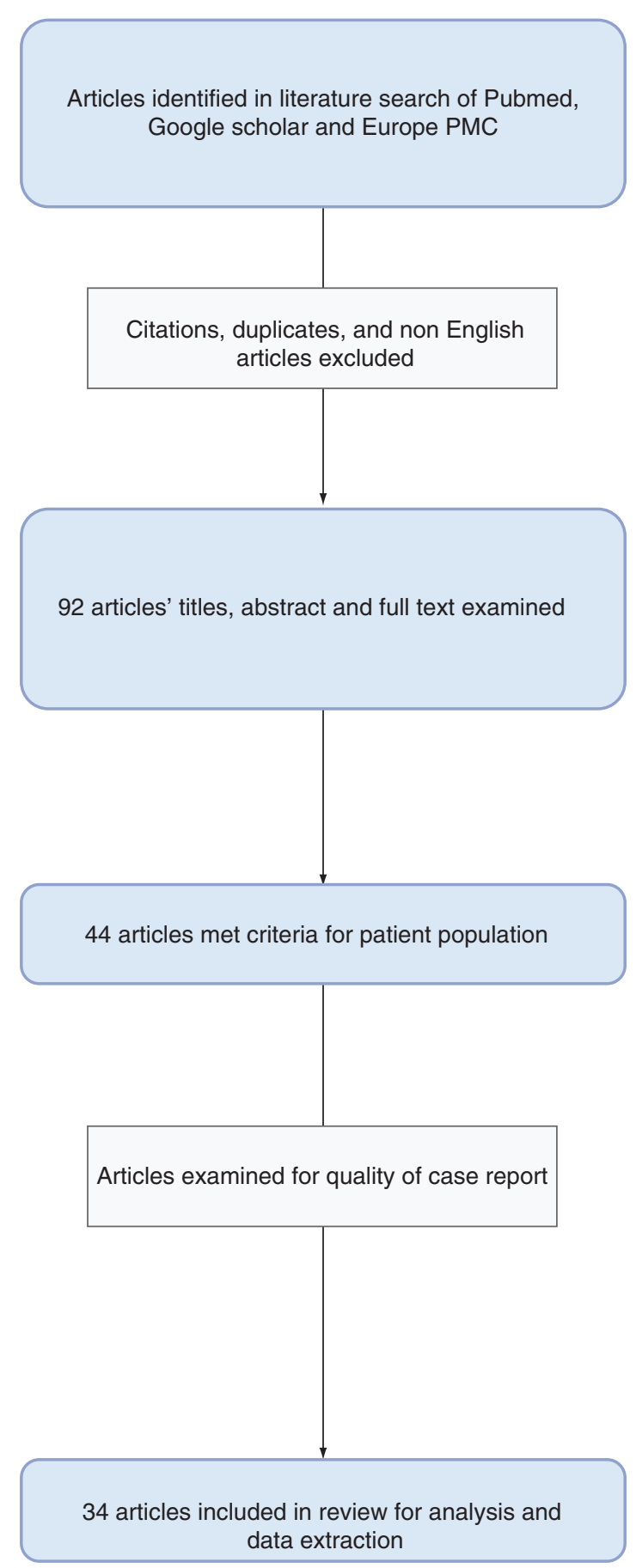

Figure 1. PRISMA flow diagram showing the process of identification, screening and selection of articles for review. 
Only papers including patients over 18 years of age with diagnosed primary gastric melanoma were included. Search results were independently assessed by reviewers, GS Mellotte and D Sabu. Any differences in opinion on the inclusion of study were approached by discussion between reviewers.

Excluded were cases of metastatic gastric lesions from other sites, mucosal melanoma of sites other than the stomach, review papers, book chapters and studies not found in the English language. There were no limits placed on date of publication.

These studies were examined for patient age, sex, endoscopic features of melanoma, treatment, histological features and mortality. Major outcomes for the studies were mortality, 12-month survival and surgery.

Data were extracted using a specifically designed questionnaire and stored in a Microsoft Excel sheet created for the purpose of this review.

\section{Results}

We identified 44 case studies of primary gastric melanoma in the literature. Given the rarity of this primary mucosal melanoma, all relevant studies were single-case reports, no case series were published. Using the tool provided by Murad et al. [6] for the methodical assessment of case reports, we reviewed each of these cases, 34 met the criteria score of greater than 4 using the scoring tool based on four categories of selection, ascertainment, causality and outcome. Given the rarity of gastric melanoma and the limited number of cases available in the literature, it was not possible to adequately assess exposure between articles; primary gastric melanoma is a rare presentation and there was no study which was able to show more than one case presenting to their center. It was important for the case studies to provide adequate description of presentation, workup and outcome to be able to draw conclusions, which can be applied to practice going forward. Similarly, there was no dose/response or challenge/rechallenge phenomenon to be assessed in any of the cases, so these metrics were removed from the assessment. Use of the scoring tool allowed for us to objectively rate single case studies on a set standard basis.

Thirty-four cases had a sufficient history, description and follow-up to extrapolate the data to use in an analysis of 1-year survival rates postdiagnosis [7-40]. The other ten cases did not meet the standard set.

The median age of patient population was 64.5 years with a range of 42-87 years. Twenty-four patients found were male. Seventeen patients were anemic at presentation.

Twenty-three of the 34 studies provided follow-up data, the mean time of follow-up was 17.1 months. Across the studies, there were 12 reported deaths at the time of publishing, with a mean time to death of 22 months. It must be noted a large amount of studies had no follow-up data listed at all or patients failed to attend their follow-up. The patient population is summarized in Table 1.

Twenty-three patients had surgical resection with curative intent. The surgeries are summarized below in Table 2. Thirteen patients (56.5\%) from the surgical cohort were alive at 1-year follow-up. This group had a mean survival time of 21 months with a range of 3-84 months. The patient cohorts and outcomes are shown in Figure 2.

Six patients had adjuvant therapy with surgery, four (66\%) had a 1-year survival. Mean survival with therapy was 17 months.

Of the 17 patients who did not receive adjuvant therapy, nine patients (52\%) were alive at 1 year. There was an overall mean survival of 22 months, range of 3-84 months.

The nonsurgical group of patients comprised 11 patients, one of whom underwent a palliative jejunostomy. The median survival of this group was 3.5 months, range 1-11 months. No patient had a 1-year survival. Four patients had adjuvant therapy with two patients still alive at publishing but no time of follow-up data available, the other two patients died at 2 and 11 months, respectively.

Eighteen patients presented with a primary tumor only. Ten patients (55\%) had 1-year survival. Mean survival across this group was 15.2 months (range: 4-84 months).

Ten patients had distant solid metastasis at initial diagnosis, the sites of metastasis are listed in Table 2. One patient had a documented 1-year survival. Mean time to death was 6.14 months in metastatic patients, with a range of 1-12 months.

Six patients had positive lymph nodes at biopsy but no evidence of distal metastasis, two patients had a 1-year survival. Mean survival in this group was 14.8 months with a range of 3-36 months.

The mean survival in patients without metastasis at diagnosis was found to be significantly different from patients with solid metastases at presentation $(\mathrm{p}=0.02)$. However, mean survival was not significantly different between patients with regional lymph node metastases and those without; $\mathrm{p}=0.36$. 


\begin{tabular}{|c|c|c|c|c|c|c|c|c|}
\hline $\begin{array}{l}\text { Patients for } \\
\text { analysis ( } n \text { ) }\end{array}$ & Study (year) & Age (years) & Sex & Presentation & $\begin{array}{l}\text { One-year } \\
\text { survival }\end{array}$ & $\begin{array}{l}\text { Follow-up } \\
\text { (months) }\end{array}$ & Endoscopic appearance & Ref. \\
\hline 1 & $\begin{array}{l}\text { Kouvaras et al. } \\
\text { (2019) }\end{array}$ & 82 & Female & Melena & Yes & 12 & Pigmented polypoid masses & [7] \\
\hline 2 & Jelincic et al. (2005) & 58 & Male & $\begin{array}{l}\text { Fatigue, epigastric pain, } \\
\text { weight loss }\end{array}$ & Yes & 24 & Gastritis and 2-cm ulcer & [8] \\
\hline 3 & Holmes et al. (2017) & 54 & Male & $\begin{array}{l}\text { Weakness, abdominal } \\
\text { pain, weight loss }\end{array}$ & Yes & 36 & Ulcerated brown tumor & [9] \\
\hline 4 & Zhou et al. (2016) & 68 & Female & Incidental & Yes & 24 & $\begin{array}{l}\text { Round mass in greater curvature of } \\
\text { the stomach }\end{array}$ & [10] \\
\hline 5 & Bahat et al. (2010) & 59 & Male & Incidental & No & 4 & Polypoidal & [11] \\
\hline 6 & $\begin{array}{l}\text { Bolzacchini } \\
\text { et al. (2016) }\end{array}$ & 72 & Male & Epigastric pain, melena & No & 6 & Ulcerated antral mass & [12] \\
\hline 7 & $\begin{array}{l}\text { Laskaratos } \\
\text { et al. (2014) }\end{array}$ & 73 & Male & Incidental & No & 12 & $\begin{array}{l}\text { Pigmented, elevated lesion } 2 \mathrm{~cm} \text { in } \\
\text { the posterior wall of the stomach }\end{array}$ & [13] \\
\hline 8 & Fotoohi et al. (2019) & 65 & Male & Dysphagia, weight loss, & No & 3 & $\begin{array}{l}\text { Bulky black mass at oesophageal } \\
\text { gastric junction }\end{array}$ & [14] \\
\hline 9 & Houissa et al. (2010) & 56 & Male & $\begin{array}{l}\text { Epigastric pain, } \\
\text { hematemesis, weight } \\
\text { loss }\end{array}$ & Yes & 84 & $\begin{array}{l}\text { Ulcerated tumor in the proximal } \\
\text { stomach }\end{array}$ & [15] \\
\hline 10 & Lufrano et al. (2007) & 67 & Female & Chest tightness/pain & Yes & 60 & Not described & [16] \\
\hline 11 & Yang et al. (2008) & 53 & Male & $\begin{array}{l}\text { Epigastric pain and } \\
\text { dysphagia }\end{array}$ & No & 11 & $\begin{array}{l}\text { Dark pigmented lesion at the gastric } \\
\text { junction }\end{array}$ & [17] \\
\hline 12 & $\begin{array}{l}\text { Noraidah } \\
\text { et al. (2003) }\end{array}$ & 76 & Male & $\begin{array}{l}\text { Fatigue, exertional } \\
\text { dyspnea }\end{array}$ & No & $\mathrm{NA}^{\dagger}$ & Large ulcerated lesion & [18] \\
\hline 13 & Loh et al. (2012) & 68 & Male & Incidental & No & 4 & Not described & [19] \\
\hline 14 & Khaliq et al. (2012) & 78 & Male & Asymptomatic & Yes & 24 & Ulcerated fundic lesion & [20] \\
\hline 15 & Kim et al. (2013) & 60 & Male & Fatigue & No & NA & Black polypoid mass & [21] \\
\hline 16 & $\begin{array}{l}\text { Konikoff } \\
\text { et al. (2019) }\end{array}$ & 74 & Male & $\begin{array}{l}\text { Epigastric pain, } \\
\text { hematemesis, melena }\end{array}$ & No & NA & $\begin{array}{l}\text { Large ulcer in lesser curvature with } \\
\text { adherent blood clot. 3-4 adjacent } \\
\text { nodules noted }\end{array}$ & [22] \\
\hline 17 & Wang et al. (2016) & 63 & Male & Right limb disorder & No & 10 & $\begin{array}{l}\text { Huge ulcer lump }\left(5.0 \times 4.0 \mathrm{~cm}^{2}\right) \text { at } \\
\text { the bottom of stomach, with } \\
\text { purplish-brown mucosa }\end{array}$ & [23] \\
\hline 18 & Alazmi et al. (2003) & 66 & Female & Anemia and weight loss & Yes & 18 & Not described & [24] \\
\hline 19 & Cho et al. (2014) & 64 & Male & Fatigue & Yes & 18 & $\begin{array}{l}\text { Ulcerated mass in the greater } \\
\text { curvature }\end{array}$ & [25] \\
\hline 20 & $\begin{array}{l}\text { Yamamura } \\
\text { et al. (2012) }\end{array}$ & 58 & Male & Fatigue, epigastric pain & Yes & 16 & $\begin{array}{l}\text { Submucosal mass with ulceration at } \\
\text { antrum }\end{array}$ & [26] \\
\hline 21 & $\begin{array}{l}\text { Dabrowski } \\
\text { et al. (2005) }\end{array}$ & 63 & Male & Progressive dysphagia & Yes & 14 & $\begin{array}{l}\text { Friable tumor extending to the } \\
\text { cardia }\end{array}$ & [27] \\
\hline 22 & Wang et al. (2019) & 66 & Female & Abdominal pain & Yes & NA & Not described & [28] \\
\hline 23 & $\begin{array}{l}\text { Callaghan } \\
\text { et al. (2018) }\end{array}$ & 67 & Male & Left chest discomfort & Yes & 20 & $\begin{array}{l}\text { Ulcerated tumor in the proximal } \\
\text { stomach }\end{array}$ & [29] \\
\hline 24 & Lim et al. (2018) & 50 & Male & $\begin{array}{l}\text { Epigastric pain, reduced } \\
\text { appetite }\end{array}$ & No & NA & $\begin{array}{l}\text { Ulcerated mass extending toward } \\
\text { antrum }\end{array}$ & [30] \\
\hline 25 & Castro et al. (2008) & 50 & Female & $\begin{array}{l}\text { Axillary } \\
\text { lymphadenopathy }\end{array}$ & No & NA & $\begin{array}{l}\text { Elevated lesion with central } \\
\text { umbilication and black hue in the } \\
\text { fundus }\end{array}$ & [31] \\
\hline 26 & $\begin{array}{l}\text { Wiewiora } \\
\text { et al. (2019) }\end{array}$ & 54 & Male & Anorexia, weight loss & No & 3 & Not described & [32] \\
\hline 27 & $\begin{array}{l}\text { Augustyn } \\
\text { et al. (2015) }\end{array}$ & 75 & Male & Melena & No & 11 & $\begin{array}{l}\text { Pigmented, ulcerated lesion with } \\
\text { irregular margins }\end{array}$ & [33] \\
\hline 28 & $\begin{array}{l}\text { Lagoudianakis } \\
\text { et al. (2006) }\end{array}$ & 42 & Male & $\begin{array}{l}\text { Abdominal pain, } \\
\text { anorexia, vomiting }\end{array}$ & No & 2 & $\begin{array}{l}\text { Upper gastrointestinal endoscopy, } \\
\text { multiple dark brown macules } \\
(2-5 \mathrm{~mm} \text { in diameter) were seen } \\
\text { within the stomach }\end{array}$ & [34] \\
\hline 29 & Liu et al. (2019) & 59 & Male & $\begin{array}{l}\text { Postprandial pain and } \\
\text { tarry stool for } 2 \text { months }\end{array}$ & No & 6 & $\begin{array}{l}\text { Polypoid mass in the cardia of the } \\
\text { stomach }\end{array}$ & [35] \\
\hline
\end{tabular}




\begin{tabular}{|c|c|c|c|c|c|c|c|c|}
\hline $\begin{array}{l}\text { Patients for } \\
\text { analysis (n) }\end{array}$ & Study (year) & Age (years) & Sex & Presentation & $\begin{array}{l}\text { One-year } \\
\text { survival }\end{array}$ & $\begin{array}{l}\text { Follow-up } \\
\text { (months) }\end{array}$ & Endoscopic appearance & Ref. \\
\hline 30 & Phillips et al. (2018) & 87 & Male & $\begin{array}{l}\text { Fatigue, weight loss, } \\
\text { melena }\end{array}$ & No & NA & $\begin{array}{l}8-\mathrm{cm} \text { pedunculated mass at the } \\
\text { greater curvature }\end{array}$ & [41] \\
\hline 31 & $\begin{array}{l}\text { Eshtiaghpour } \\
\text { et al. (2014) }\end{array}$ & 63 & Female & Abdominal pain & No & NA & $\begin{array}{l}\text { Black lesions in the greater } \\
\text { curvature of the stomach }\end{array}$ & [36] \\
\hline 32 & Liang et al. (1995) & 78 & Female & $\begin{array}{l}\text { Abdominal pain, loss of } \\
\text { appetite, weight loss, } \\
\text { anemia }\end{array}$ & No & 1 & $\begin{array}{l}12 \text { small darkly pigmented tumors. } \\
\text { Some lesions were raised and } \\
\text { volcanoid, some were flat }\end{array}$ & [37] \\
\hline 33 & Slater et al. (2014) & 63 & Female & Intermittent vomiting & No & NA & 5-mm polyps in the body & [38] \\
\hline 34 & Song et al. (2014) & 50 & Female & $\begin{array}{l}\text { Epigastric discomfort, } \\
\text { vomiting }\end{array}$ & No & 4 & Friable mass at lesser curvature & [39] \\
\hline
\end{tabular}

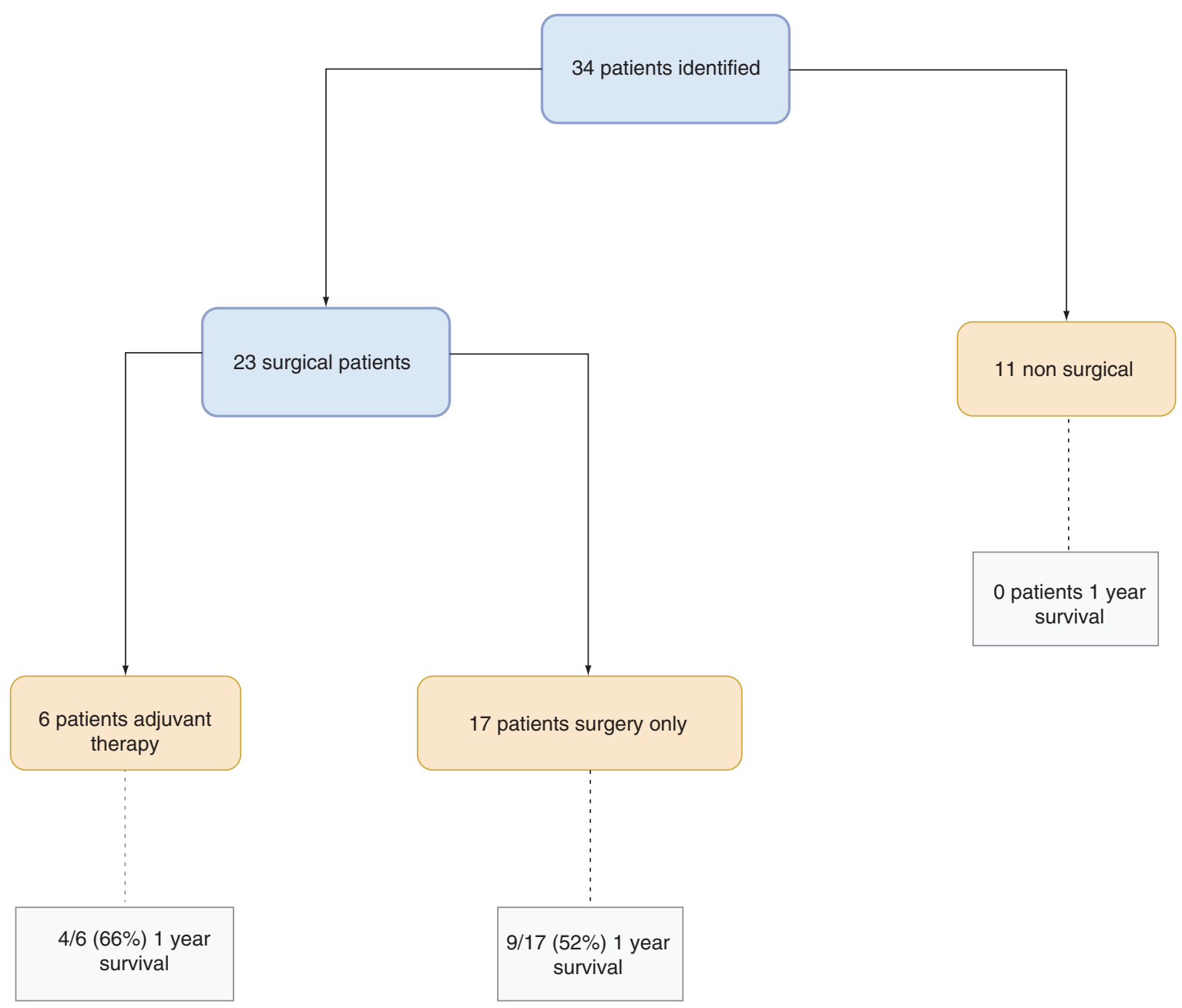

Figure 2. Patient 1-year survival outcomes in surgical and nonsurgical treatment groups for primary gastric melanoma.

Comparison of mean survival between the groups allowed us to assess whether there was a significant difference in patient outcome with intervention. Mean survival of the surgical group with treatment was 17.67 months $( \pm 12.4)$ versus 22.62 months $( \pm 23.23)$ in the nonadjuvant group. This difference was not found to be statistically significant when the means were compared, $\mathrm{p}=0.6274$. 
Table 2. Patient's surgical procedure and distal or locoregional metastatic sites.

\begin{tabular}{|c|c|c|c|c|c|}
\hline $\begin{array}{l}\text { Patients for } \\
\text { analysis (n) }\end{array}$ & Study (year) & Surgical procedure & Treatment regimen & Metastatic at presentation & Ref. \\
\hline 1 & Kouvaras et al. (2019) & Partial distal gastrectomy & $\begin{array}{l}\text { Pembrolizumab followed } \\
\text { by ipralimumab }\end{array}$ & Pulmonary & [7] \\
\hline 2 & Jelincic et al. (2005) & Partial gastrectomy with splenectomy & Interferon & Nil & [8] \\
\hline 3 & Holmes et al. (2017) & $\begin{array}{l}\text { Subtotal gastrectomy, appendectomy and } \\
\text { splenectomy }\end{array}$ & Chemo/radiation $\ddagger$ & Regional lymph node and appendix & [9] \\
\hline 4 & Zhou et al. (2016) & Total gastrectomy & Oral immunotherapeutic & Nil & [10] \\
\hline 5 & Bahat et al. (2010) & Total gastrectomy & Dacarbazine & Local node & [11] \\
\hline 6 & Bolzacchini et al. (2016) & Surgery ${ }^{\dagger}$ & Pembrolizumab & Nil & [12] \\
\hline 7 & Laskaratos et al. (2014) & Distal gastrectomy & Nil & Nil & [13] \\
\hline 8 & Fotoohi et al. (2019) & $\begin{array}{l}\text { Distal esophagectomy and proximal } \\
\text { gastrectomy }\end{array}$ & Refused by patient & Local & [14] \\
\hline 9 & Houissa et al. (2010) & $\begin{array}{l}\text { Extended total gastrectomy with } \\
\text { splenectomy }\end{array}$ & Nil & Nil & [15] \\
\hline 10 & Lufrano et al. (2007) & Gastrectomy & Nil & Nil & [16] \\
\hline 11 & Yang et al. (2008) & $\begin{array}{l}\text { Esophagogastrectomy, lymphadenectomy, } \\
\text { distal pancreatectomy, splenectomy and } \\
\text { transverse colectomy }\end{array}$ & Nil & Regional lymphadenopathy & [17] \\
\hline 12 & Noraidah et al. (2003) & Open sleeve gastrectomy & Nil & Nil & [18] \\
\hline 13 & Loh et al. (2012) & Partial gastrectomy & Nil & Bladder & [19] \\
\hline 14 & Khaliq et al. (2012) & Partial gastrectomy & Nil & Nil & [20] \\
\hline 15 & Kim et al. (2013) & Partial gastrectomy & Nil & Nil & [21] \\
\hline 16 & Konikoff et al. (2019) & $\begin{array}{l}\text { Proximal gastrectomy, splenectomy and } \\
\text { limited small bowel resection with } \\
\text { end-to-end anastomosi }\end{array}$ & $\begin{array}{l}\text { Did not attend for } \\
\text { follow-up }\end{array}$ & $\begin{array}{l}\text { Multiple metastatic nodules were also } \\
\text { seen in the ileum, root of the } \\
\text { mesentery, para-iliac nodes, para-aortic } \\
\text { nodes and the liver }\end{array}$ & [22] \\
\hline 17 & Wang et al. (2016) & Proximal stomach resection & Nil & Brain, liver & [23] \\
\hline 18 & Alazmi et al. (2003) & $\begin{array}{l}\text { Resection of the stomach, spleen and } \\
\text { greater omentum and D2 } \\
\text { lymphadenectomy with additional excision } \\
\text { of the lymph nodes of the liver cavity }\end{array}$ & Nil & Nil & [24] \\
\hline 19 & Cho et al. (2014) & $\begin{array}{l}\text { Subtotal gastrectomy with lymph node } \\
\text { dissection }\end{array}$ & Nil & Nil & [25] \\
\hline 20 & Yamamura et al. (2012) & Subtotal gastrectomy with splenectomy & Refused by patient & Nil & [26] \\
\hline 21 & Dabrowski et al. (2015) & Total gastrectomy & Nil & Nil & [27] \\
\hline 22 & Wang et al. (2019) & Total gastrectomy & Nil & Nil & [28] \\
\hline 23 & Callaghan et al. (2018) & Total gastrectomy and lymphadenectomy & Nil & Local nodes & [29] \\
\hline 24 & Lim et al. (2018) & Palliative jejunostomy & Nil & Nil & [30] \\
\hline 25 & Castro et al. (2008) & Nil & Dacarbazine/cisplatin & Regional and axillary lymph nodes & [31] \\
\hline 26 & Wiewiora et al. (2019) & Nil & Chemotherapy $\ddagger$ & Lung, pancreas & [32] \\
\hline 27 & Augustyn et al. (2015) & Nil & $\begin{array}{l}\text { Vemurafenib followed by } \\
\text { ipilimumab }\end{array}$ & Liver and regional lymph nodes & [33] \\
\hline 28 & $\begin{array}{l}\text { Lagoudianakis } \\
\text { et al. (2006) }\end{array}$ & Nil & Chemotherapy $\ddagger$ & Liver & [34] \\
\hline 30 & Phillips et al. (2018) & Nil & Radiotherapy $\ddagger$ & Nil & [41] \\
\hline 31 & $\begin{array}{l}\text { Eshtiaghpour } \\
\text { et al. (2014) }\end{array}$ & Nil & Nil & Liver & [36] \\
\hline 32 & Liang et al. (1995) & Nil & Nil & Liver & [37] \\
\hline 33 & Slater et al. (2014) & Nil & Nil & Brain & [38] \\
\hline
\end{tabular}

$\dagger$ Exact surgical procedure not published in the article.

¥Treatment regimen not published in the article. 
However, comparison of the mean survival between the surgical 21.05 months $( \pm 20.2)$ and nonsurgical group 4.5 months ( \pm 3.61$)$ was found to be statistically significant with p-value of 0.0086 (CI: -28.5944 to -4.5056 ).

\section{Discussion}

\section{Development}

Primary mucosal melanomas are thought to arise from the melanocytes found within the epithelial lining of mucosal membranes. These melanocytes have been found in the lining of the esophagus, stomach and intestine [2]. This is not confined to patients who are diagnosed with a malignancy, presence of melanocytes within the upper GI tract has been demonstrated in $7.7 \%$ of the healthy adult population [41]. This is more frequently seen in the esophagus and the anorectum but the mechanism for the development of these melanocytes is poorly understood [2,42]. There are three primary theories for development of melanoma in the GI tract. First, melanoblastic cells have been observed to migrate to the GI tract in both healthy patients and those with esophageal cancer; migration is abnormal and thought to occur during embryogenesis [43]. This provides a mechanism for the development of melanoma within the esophageal tract [42].

Second, amine precursor uptake and decarboxylation cells arising from the neural crest may differentiate into melanocytes; the exact process by which this occurs is not yet known but this is another putative mechanism for the development of mucosal melanoma [44]. Schwannian neuroblast cells also arise from the neural crest and play a role in the autonomic innervation of the gut. They have been linked with tumorigenesis and may differentiate into primary melanoma [45]. Interestingly melanosis has been observed in the esophagus and stomach of patients with diagnosed rectal melanoma [45,46]. This would suggest that melanosis was present that gave rise to a mucosal melanoma and may help suggest a pathway for the pathogenesis for melanoma. An in situ component seen at histology also gives support to the diagnosis of a primary melanoma and not a metastatic deposit [42].

\section{Epidemiology}

The incidence of primary gastric melanoma does not correlate with UV exposure or other risk factors associated with cutaneous melanoma [47]. There is no correlation with race, although there is evidence that incidence appears to increase with age [48]. The higher incidence of cutaneous melanoma in the Caucasian population gives a false impression that mucosal melanoma is more common in other ethnic populations but in reality there is no absolute difference across groups. This also suggests there may be a different pathogenesis and underlying pathway contributing to the disease development but there has been no link to an ethnic group at higher risk of primary mucosal melanoma at this point. Ethnicity was not reported in a sufficient number of cases in our review to be able to estimate a population at higher risk.

No significant risk factor has been found for the development of a primary gastric melanoma. Studies have shown that an increased risk of oral melanosis and oropharyngeal mucosal melanoma is related to smoking but this has not been connected to upper GI melanoma [48].

The incidence of mucosal melanoma is reported to peak around the age of 70 with a higher incidence in women compared with males [49,50]. This is an older peak incidence than that seen in cutaneous melanoma. In our own review of studies, we found a higher incidence in males, with 24 of 34 cases male and a mean age of 63 years, only two cases were reported in individuals under 50 years of age.

\section{Pathology}

The histological diagnosis of mucosal melanoma is the gold standard. Microscopic examination relies on the identification of melanin. Cells may show characteristics of high pleomorphism and display prominent nucleoli; they may appear epithelioid or spindled cells that are often arranged in a sheet-like pattern (Figure 3). Mucosal melanoma with little to no melanin often proves a significant challenge to diagnose leading to a delay in treatment for patients.

Immunohistochemical staining is crucial for diagnosis in patients who do not express melanin. S100, melanoma antigen recognized by $\mathrm{T}$ cells (Melan-A) (Figure 4), and human melanoma black (HMB45) (Figure 5) are frequently used in the diagnosis of melanoma [39,51,52]. Sox10, a transcription marker for neural crest cells, is sensitive and specific for the diagnosis of melanoma [53]. Vimentin is a major constituent of the intermediate filament family of proteins. Increased expression is seen in melanoma but can also be seen in epithelial tumors in the gut, lungs, CNS, breast and skin making it a nonspecific marker of malignancy [54]. 
(A)

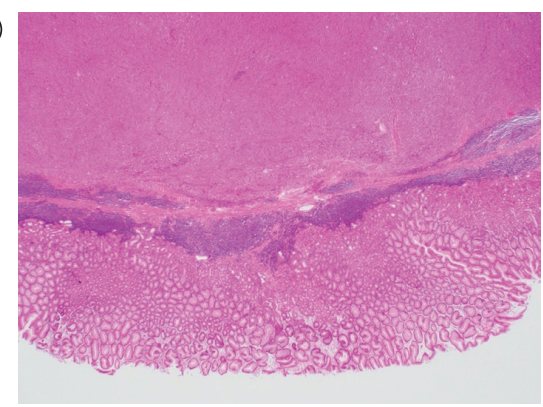

(B)

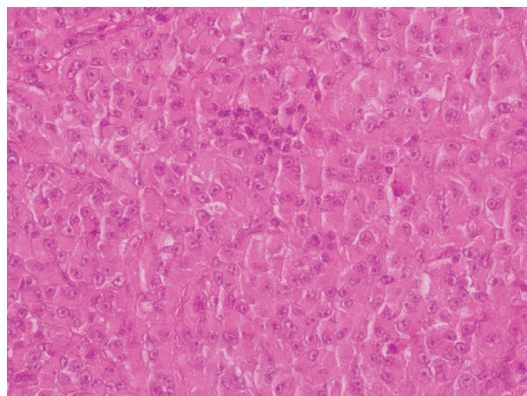

Figure 3. Histological images of gastric melanoma. Gastric melanoma biopsy with gastric mucosa (hematoxylin-eosin staining, 2x (A) and 40x (B) magnification).

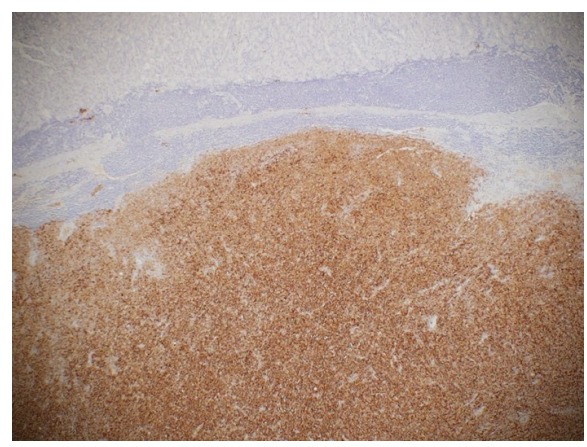

Figure 4. Gastric melanoma with positive HMB45 stain.

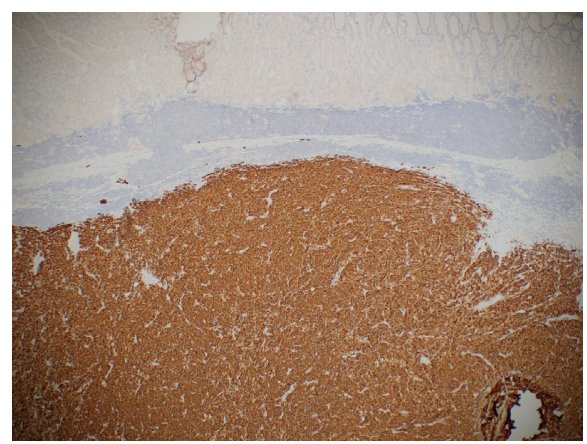

Figure 5. Gastric melanoma with positive Melan-A stain.

\section{Genetics}

The genetics of UV- and non-UV-related melanoma broadly vary. The behavior of mucosal melanoma may be explained by the expression of genetic factors.

$B R A F$ V600e is a RAS-regulated serine-threonine protein kinase that mediates cell growth and malignant transformation [53]. The $B R A F$ gene mutation was identified in five patients with primary gastric melanoma in our review. This was the only gene mutation reported across all 34 cases, however, it is not clear the scope of testing the tumors went or if all 34 patients had gene testing performed as part of workup. Overall, incidence is low in mucosal melanoma, occurring in less than $10 \%$ of cases. BRAF mutations are seen more frequently in cutaneous melanoma and melanotic nevi compared with mucosal melanoma [55].

Neuroblastoma $R A S$ mutations, a GTPase-controlling gene, is recognized in the development of melanoma with rates of $15-22 \%$ in cutaneous melanoma and 5\% in mucosal lesions, although the rates vary between sites of mucosal melanoma [56-58].

The KIT mutation is more commonly associated with acral lentiginous melanoma subtype than cutaneous and has been described in up to $23 \%$ of cases [55]. A kinase inhibitor, it has also been found to be expressed in 15-21\% of mucosal melanomas suggesting a different developmental pathway to that of cutaneous melanoma [55,59]. 
The cyclin-dependent kinase pathway has a proven link to melanoma development. The gain of $C K 4$ or $C K 6$ or the loss of $C D K N 2 A$ have been shown to play a role in the development of mucosal melanoma in certain populations. Another cell cycle gene, CCND1, is amplified in approximately $25 \%$ of mucosal melanomas, with a lower rate of $2-13 \%$ in UV-associated melanoma [60]. This pathway has been shown to be more significant in non-UV-related melanoma [49].

The PDGF receptor $\alpha$-polypeptide is a separate pathway found in a low number of melanomas but a relatively higher percentage of mucosal and acral compared with sun exposure-related melanoma [61].

Taken together, all these findings suggest a very different genetic pathway for the development of mucosal melanoma from that of cutaneous melanoma, providing new avenues for research and treatment.

\section{Clinical presentation \& investigation}

Presentation of primary gastric melanoma can closely mimic other gastric cancers or more benign conditions. Vague systemic symptoms of generalized abdominal pain, loss of appetite, weight loss and fatigue are common. Both primary and metastatic gastric melanoma may also present with localized discomfort, dysphagia, hematemesis or melena. Upper GI bleeds associated with melanoma have presented as acute upper GI bleeds but the majority of cases present as stable, chronic bleeds and anemia is commonly found at initial workup. In some cases, the presentation can be indolent with patients having suspicious GI lesions under surveillance and workup for years prior to a diagnosis of melanoma being made [62].

\section{Radiological appearance}

There are limited descriptions of the radiological appearance of gastric melanoma in our review. CT appearance of gastric melanoma lesions are described with thickened gastric wall and discrete soft-tissue masses $[17,24,26]$. This alone will not discriminate gastric melanoma from other gastric cancers. Melanomas tend to be a vascular tumor and enhancement with intravenous contrast can help improve detection.

The appearance of melanoma on MRI is influenced by the presence of melanin, as melanin is paramagnetic. Melanotic lesions appear hyperintense on T1 sequencing but have low signal intensity on T2-weighted images.

PET/CT with fluorodeoxyglucose ${ }^{18} \mathrm{~F}$ (FDG) is a powerful clinical tool for assessing spread in metastatic melanoma. It is more useful than conventional imaging for highlighting areas of distant spread or localizing disease not otherwise seen on CT alone [63,64].

\section{Endoscopic appearance}

The appearance of GI mucosal melanoma can vary greatly at endoscopy. Forty articles found during the literature search had description of endoscopic appearances. Over half the cases describe a large ulcerated or polypoidal mass varying in size $[7,10,23,36]$. Friability of the overlying mucosa is frequently mentioned in description but melanosis of the stomach is not ubiquitous across the whole cohort. There are multiple lesions in many reports, with one case describing over a hundred black lesions throughout the stomach and duodenum, varied in size and shape [65]. One case described a pedunculated mass, one a volcano-like tumor [57], and another with central umbilication. Benign-appearing lesions have also been diagnosed with one biopsy of $5 \mathrm{~mm}$, benign-appearing, gastric polyps and another appearance described as a chronic gastritis. Part of the challenge at endoscopy and histology arises with amelanotic lesions. Ulcers have been described as pigmentated with colors ranging from black to brown to red across the literature. Some gastric melanomas are not tumoral masses but present as simple appearing ulcers.

Tissue diagnosis from gastric biopsy at endoscopy can be difficult. Biopsies are often taken at the edge of lesions to reduce the risk of bleeding, this combined with a varied appearance at microscopy can make diagnosis difficult [52]. This is highlighted by the case Bahat et al., where melanoma was diagnosed on follow-up endoscopy and biopsy for a nonhealing ulcer after 8 weeks, delaying the management [11]. Lufrano et al. describe a case of a biopsy of a simple appearing 5-mm gastric polyp histologically positive for a melanoma [16].

There are cases documenting use of endoscopic ultrasonography to help diagnosis of lesions in the esophagus [6668], gallbladder [62,67] and anorectal disease [69] but it is not a part of the routine assessment of lesions.

Ultimately the diagnosis is based on a combination of histology and immunohistochemistry. It is of critical importance in amelanotic lesions where endoscopic appearances can be deceptive. 


\section{Differentiation of primary versus metastatic melanoma}

Given the exceedingly low incidence of primary gastric melanoma, it is imperative that when gastric melanoma is discovered that other potential sites of primary disease are examined. This includes a full body dermatological examination and ophthalmology review. There is also evidence that colonoscopy is important to rule out a potential site of primary disease [9]. The use of nuclear PET scan with fluoride-18 FDG avid markers has been shown to be effective in both melanoma and gastric carcinoma [50,70]. PET scan may be of value but no formal guidelines exist.

There are no formal diagnostic criteria for the primary gastric melanoma. As such a full clinical and diagnostic investigation is performed on an ad hoc basis between centers and physicians. Blecker $e t$ al. suggested guidelines for definition of primary gastric melanoma: no history of invasive or in situ cutaneous melanocytic lesion in addition to in situ change of the GI epithelium [54,71]. Song et al. [39] describe the diagnostic criteria for their case as a single, pathology proven lesion within the stomach without other concurrent lesions or a history of melanoma. They also stipulated the disease-free survival of at least 12 months postdiagnosis to exclude possible metastatic disease with regressed primary [52]. These criteria have not yet been validated and as our review has shown the 1-year survival can vary significantly.

As with diagnostic criteria, there is no formal staging system in place for primary gastric melanoma. Clark's level can only be applied to cutaneous lesions. Breslow thickness does not have the same prognostication value as in cutaneous due to a difference in the underlying layers. In practical settings, the tumor, node, metastasis (TNM) staging used in other gastric cancers is extrapolated for use in melanoma of the stomach.

\section{Treatment}

Evidence-based guidelines for the management of mucosal melanomas are still underway. Large-scale clinical trials have not been undertaken primarily due to the rare nature of disease and often late presentation with disseminated disease. Most current regimes are extracted from data for primary cutaneous melanoma.

\section{Surgery}

For localized upper GI tract melanomas, surgical resection with negative pathologic margin can be curative. Within the surgical cohort, the surgical procedure undertaken varied, driven by clinical decision making, due to tumor size and location within the stomach.

Case reports on adjuvant radiation treatment in mucosal melanoma have shown some improved local disease control but no overall survival benefit or prolonged disease-free survival [72].

Adjuvant treatment options include interferon alpha, chemotherapy, targeted treatment and immunotherapy or combination treatments. Until 2017, IFN- $\alpha$ was the only adjuvant treatment in melanoma that showed some survival benefit based on the ECOG E1684 study published as early as 1997 but even this was limited to cutaneous melanomas [73]. One patient in our study was treated with interferon postpartial gastrectomy and splenectomy with a survival time of 24 months postdiagnosis [24].

With two patients receiving pembrolizumab and a third patient receiving dacarbazine, there were limited data on adjuvant therapy available for our cohort. Two other patients received adjuvant therapy but their actual regime was not documented. There is limited evidence for adjuvant therapy in primary gastric melanoma, patients have been treated with regimes extrapolated from mucosal and cutaneous melanomas.

\section{Metastatic melanoma}

Unfortunately, most upper GI melanomas are metastatic at presentation due to nonspecific symptoms and resulting delays in diagnosis. Surgical resection is often not possible in these cases and systemic treatment options should be considered. For patients not suitable for systemic treatment, palliative radiation has been used effectively for symptom control [38]. Local endoscopic therapy can also be used in this context to control bleeding or reduce transfusion requirements.

\section{Chemotherapy}

Before the era of immunotherapy, treatment options for patients with advanced mucosal melanoma were very limited. Melanoma is a chemotherapy resistant tumor and tends to have lower response rates than other forms of cancer. Historically dacarbazine chemotherapy has shown response rates of about $13.4 \%$, but has no proven survival benefit [74]. A retrospective analysis of 95 Korean patients with metastatic melanoma, who received dacarbazine showed similar response rates in cutaneous and mucosal melanoma at $26.3 \%$ [75]. Other clinical trials investigated 
the combination of dacarbazine with other chemotherapy agents like cisplatin, vinblastine and biologic agents such as IFN- $\alpha$, but failed to demonstrate significantly higher response rates compared with dacarbazine monotherapy [7678].

\section{Targeted treatment}

Understanding the molecular basis of melanoma has led to the development of targeted treatments with improved disease control. All biopsies should be tested for driver mutations of BRAF, KIT and NRAS.

Where the $B R A F$ mutation is positive a survival benefit has been seen with dabrafenib in combination with trametinib, a mitogen-activated protein kinase (MEK) 1 and 2 inhibitor. Their combination has proven beneficial to overcome $B R A F$ inhibitor resistance. In 2015, results of a Phase III trial showed better overall survival (at 12 months was 72 vs $65 \%$ ) with combination treatment compared with monotherapy with BRAF inhibitor [67]. KIT mutations or amplification in exon 11 and 13 exhibited a beneficial response to KIT inhibitors such as imatinib or dasatinib [79]. Results of a Phase II study published in 2011 showed 23.3\% overall response rate with imatinib [80]. The study included 11 patients with mucosal melanoma but no data relating to this subgroup analysis were published.

NRAS mutation shows similar incidence rates of $15-20 \%$ in all melanoma subtypes and is associated with $B R A F$ inhibitor resistance [81]. Mutated NRAS triggers mitogen-activated protein kinase signaling pathway, which in turn activates MEK. Hence, MEK inhibitors as binimetinib, trametinib are used in NRAS mutant cutaneous melanoma. There are ongoing trials using MEK inhibitors in combination with $C D K 4 / 6$ inhibitors in cutaneous melanoma. Trials looking at the benefit of these agents in mucosal melanoma are needed.

\section{Immunotherapy}

Combining chemotherapy with immunotherapy has proven beneficial in cutaneous melanoma but needs more clinical trials to extend their use in mucosal melanoma [82]. Immune check point inhibitors targeting programmed death ligand 1(PD-L1), its receptor PD-1 and cytotoxic T-lymphocyte-associated protein- 4 have all proven beneficial in different types of cancer. These agents have shown benefit when used alone or in combination in various clinical trials with cutaneous melanoma. In 2016, a multicenter retrospective cohort analysis looked at response rates to anti-PD-1 agents in patients with mucosal melanoma and was found to be consistent with cutaneous melanomas [82]. In 2017, a much larger pooled analysis looked at use of these agents in mucosal melanoma. The conclusion was in favor of their use in mucosal melanoma although objective response rates were lower [83].

Ipilimumab has been the US FDA approved since 2011 for treatment of metastatic melanoma. Ipilimumab, either alone at $3 \mathrm{mg} / \mathrm{kg}$ in previously treated patients or at $10 \mathrm{mg} / \mathrm{kg}$ in combination with dacarbazine in treatment-naive patients, improved overall survival while exhibiting a manageable safety profile in two randomized controlled Phase III trials [84]. In 2014, nivolumab and pembrolizumab were approved for use in patients progressing on ipilimumab therapy. The CheckMate 067 study published in 2015 showed the modest benefit in combining ipilimumab and nivolumab compared with either agent alone. Combination immunotherapy treatment in mucosal melanoma showed $40 \%$ grade 3 or 4 events and should be used in patients with good performance status [85].

\section{Prognosis}

The low number of cases in the literature makes prognostication of primary gastric melanoma difficult. Moreover, most clinical trials do not specify location of mucosal melanoma, making interpretation of the data difficult. Patients tend to present later than other forms of melanoma. This is due to a combination of poorly localized symptoms in addition to a diagnostically challenging disease.

The presence of positive lymph nodes may not have significant impact on a 5-year survival but the presence of solid metastases has been associated with a poor prognosis in mucosal melanomas.

Presence of satellite lesions has not been found to be significant in cutaneous disease [86]. In our review, we did not encounter sufficient descriptions of satellite lesions to make a comment but locoregional metastases may have an impact upon survival.

From our review, we see that without early surgical intervention prognosis was dire. No patient survived beyond 11 months without surgery. There was no clear difference in survival of patients who received treatment and those who did not in the absence of surgery. 


\section{Conclusion}

Primary gastric melanoma is a rare condition in clinical practice with fewer than 50 cases reported worldwide. While gastric cancer is the fifth most commonly diagnosed cancer worldwide, mucosal melanoma accounts for just $0.03 \%$ of new cancer diagnoses [87].

Our review shows that surgical intervention in gastric melanoma is necessary for positive outcomes for these patients. With a 1 -year survival of $56.5 \%$ in our cohort of studies, the most significant factor for survival was the absence of metastasis, highlighting the need for earlier diagnosis. The advent of targeted therapies can help further improve the survival of these patients postoperatively.

Even with surgery, there was still a high 1-year mortality rate from gastric melanoma. The surgical cohort may also fare better as they are presenting earlier with less advanced disease, we also could not comment sufficiently on co-morbidities within each group. As such the surgical cohort will have a better prognosis from the beginning. Regardless of this, our review suggests that for a patient to have any significant improvement in prognosis then surgical options must be considered.

There are limitations to our review given that these were single cases across different health systems, countries and time periods. The information was further limited by differing length of follow-up and patient survival ongoing at the time of publishing, limiting extrapolation of data accurately. However, given the rarity of this disease there are no ongoing trials in place at present to help extend the current base of knowledge. The review shows that individual case studies can help guide management of rare diseases.

\section{Future perspective}

The genetics of mucosal melanoma show us that the pathway differs from that of the more common cutaneous melanoma with both patient cohort and risk factors differing between both diseases. This means that optimumtargeted therapies used in primary gastric melanoma may differ from those used in cutaneous disease and highlight the need for randomized control trials. Given the rarity of this disease, a trial is extremely difficult to undertake but understanding of the genetics and targeted therapies may provide new avenues to treatment as an adjunct to surgical management.

\section{Summary points}

- Primary gastric melanoma is an extremely rare clinical condition with a poor prognosis at diagnosis.

- Distal solid metastases at diagnosis are significantly reduced 1-year survival. Local lymph node metastases do not significantly impact survival.

- Mean survival of the surgical group with treatment was 17.67 months ( \pm 12.4 ) versus 22.62 months $( \pm 23.23)$ in the nonadjuvant group. This difference was not statistically significant.

- Comparison of the mean survival between the surgical 21.05 months $( \pm 20.2)$ and nonsurgical group 4.5 months $( \pm 3.61)$ was statistically significant.

- Appearances can vary greatly at endoscopy and lesions can appear without melanin.

- Immunohistochemistry is vital at histological workup for identification of gastric melanoma, it is critical in amelanotic lesions.

- Full clinical and ophthalmological examination should be undertaken to outrule spread from a primary cutaneous lesion.

- Positron emission tomography/computed tomography is the most useful adjunct to clinical workup for assessing metastatic spread.

- Surgical options should be offered to patients where suitable, for improved prognosis.

- Treatment regimens are extrapolated from cutaneous melanoma but genotyping of lesions may help better direct future treatments.

\section{Author contributions}

GS Mellotte drafted manuscript, developed search protocol, reviewed search results and papers for inclusion. D Sabu drafted manuscript, reviewed search results for inclusion. M O'Reilly contributed to selection criteria and provided insight on selection criteria. A O'Connor provided statistical expertise and helped develop the risk of bias strategy. R McDermott helped draft the manuscript and provided feedback the final manuscript. BM Ryan read, provided feedback and approved the final manuscript. 


\section{Acknowledgments}

The authors thank Michael Jeffers and Daniele-Mario DiCapua of the Histopathology Department, Tallaght University Hospital for providing the histopathology images for this paper.

\section{Financial \& competing interests disclosure}

The authors have no relevant affiliations or financial involvement with any organization or entity with a financial interest in or financial conflict with the subject matter or materials discussed in the manuscript. This includes employment, consultancies, honoraria, stock ownership or options, expert testimony, grants or patents received or pending, or royalties.

No writing assistance was utilized in the production of this manuscript.

\section{Open access}

This work is licensed under the Attribution-NonCommercial-NoDerivatives 4.0 Unported License. To view a copy of this license, visit http://creativecommons.org/licenses/by-nc-nd/4.0/

\section{References}

Papers of special note have been highlighted as: $\bullet$ of interest

1. Ettahri H, Elomrani F, Elkabous $\mathrm{M}$ et al. Duodenal and gallbladder metastasis of regressive melanoma: a case report and review of the literature. J. Gastrointest. Oncol. 6(5), E77-E81 (2015).

2. Mihajlovic M, Vlajkovic S, Jovanovic P, Stefanovic V. Primary mucosal melanomas: a comprehensive review. Int. J. Clin. Exp. Pathol. 5(8), 739-753 (2012).

3. Mcgovern VJ. Spontaneous regression of melanoma. Pathology 7(2), 91-99 (1975).

4. Higgins JP, Thomas J, Chandler J et al. Cochrane Handbook for Systematic Reviews of Interventions. Version 6.0 (updated July 2019). (2019).

5. Moher D, Liberati A, Tetzlaff J, Altman DG. Preferred reporting items for systematic reviews and meta-analyses: the PRISMA statement. BMJ 339, b2535 (2009).

6. Murad MH, Sultan S, Haffar S, Bazerbachi F. Methodological quality and synthesis of case series and case reports. BMJ Evid.-Based Med. 23(2), 60-63 (2018).

7. Kouvaras S, Rokkas T, Goga H et al. Multifocal gastrointestinal melanoma. J. Gastrointestin. Liver Dis. 28, 237-240 (2019).

8. Jelincic Z, Jakic-Razumovic J, Petrovic I, Cavcic AM, Unusic J, Trotic R. Primary malignant melanoma of the stomach. Tumori 91(2), 201-203 (2005).

9. Holmes A, Chung J. Two cases of primary extracutaneous melanoma: primary gastric melanoma and primary melanoma of the lung. Med. Case Rep. 3(4), 39 (2017).

10. Zhou Y, Xie B, Duan Y et al. Case report: primary gastric malignant melanoma might originate from amine precursor uptake and decarboxylation cells. Int. J. Clin. Exp. Pathol. 9(12), 13003-13009 (2016).

11. Bahat G, Saka B, Colak Y, Tascioglu C, Gulluoglu M. Metastatic gastric melanoma: a challenging diagnosis. Tumori 96(3), 496-497 (2010).

- Good case showing the difficulty in diagnosis and workup of primary gastric melanoma.

12. Bolzacchini E, Marcon I, Bernasconi G, Pinotti G. Primary melanoma of the stomach treated by BRAF inhibitor and immunotherapy. Digest. Liver Dis. 48(8), 974 (2016).

13. Laskaratos F-M, Gillmore R, Clark I, Despott EJ. Dark macules in the upper gastrointestinal tract: an ominous sign. Digest. Liver Dis. 46(12), 1133 (2014).

14. Fotoohi A, Ghaderi B, Rajabnia M, Ramezani R, Hajati AR. A case report of stomach and esophagus melanoma with liver metastases in a 63-year-old woman. Chronic Dis. J. 7(1), 62-65 (2019).

15. Houissa F, Bouzaidi S, Mouelhi L et al. Diffuse primary malignant melanoma of the upper gastrointestinal tract. Gastroen. Clin. Biol. 34(1), 85-87 (2010).

16. Lufrano M, Storch I, Feldstein R, Costable J, Gitman M. Metastatic melanoma in a dialysis patient with vomiting diagnosed by gastric polyp biopsy. Am. J. Gastroenterol. 102, S343 (2007).

17. Yang JY-M, Krishna GS, Macleod C, Oosthuysen W. Primary gastric mucosal melanoma. N. Z. Med. J. 121(1279), 96-99 (2008).

18. Noraidah M, Jasmi A. Malignant melanoma of the gastrointestinal tract presenting as a bleeding gastric ulcer. Malays. J. Pathol. 25(1), 57-61 (2003).

19. Loh W-L, Ngoi SS, Thomas A, Chan HS. Primary gastric melanoma: report of a case treated with surgical resection. Eur. J. Cancer Clin. Oncol. 4(1), 65 (2012).

20. Khaliq A, Siddappa PK, Thandassery RB et al. Melanoma of stomach. J. Gastrointest. Cancer 43(4), 630-633 (2012). 
21. Kim NR, Lee WK, Chung DH. Primary gastric melanoma with rhabdoid features: a case report. Korean J. Pathol. 47(6), 606-609 (2013).

22. Konikoff T, Manzur LH, Gingold-Belfer R. Epigastric pain and melena induced by primary gastric melanoma. Clin. Gastroenterol. Hepatol. 17(9), e104 (2019).

23. Wang L, Zong L, Nakazato H et al. Primary advanced esophago-gastric melanoma: a rare case. World J. Gastroenterol. 22(11), 3296-3301 (2016).

24. Alazmi WM, Nehme OS, Regalado JJ, Rogers AI. Primary gastric melanoma presenting as a nonhealing ulcer. Gastrointest. Endosc. 57(3), 431-433 (2003).

25. Cho JM, Lee CM, Jang YJ et al. Primary gastric malignant melanoma mimicking adenocarcinoma. J. Gastric. Cancer 14(4), 279-283 (2014).

26. Yamamura K, Kondo K, Moritani S. Primary malignant melanoma of the stomach: report of a case. Surg. Today 42(2), 195-199 (2012).

27. Dabrowski A, Zinkiewicz K, Szumilo J et al. Unusual clinical course of metachronous melanomas of the upper digestive system. World J. Gastroenterol. 11(14), 2197-2199 (2005).

28. Wang J, Yang F, Ao WQ, Liu C, Zhang WM, Xu FY. Primary gastric melanoma: a case report with imaging findings and 5-year follow-up. World J. Gastroenterol. 25(44), 6571-6578 (2019).

29. Callaghan GM, Kelleher FC, Ridgway PF, Crowther S, Alakkari A, Ryan BM. A case of primary gastric melanoma exhibiting a rare BRAF V600R mutation. Eur. J. Case Rep. Intern. Med. 5(3), 000749 (2018).

30. Lim A, Alabert F, Baudon J et al. Primary gastric melanoma with a haemorrhagic small intestine metastasis. Acta Endosc. 48(1), 30-32 (2018).

31. Castro C, Khan Y, Awasum M et al. Case report: primary gastric melanoma in a patient with dermatomyositis. Am. J. Med. Sci. 336(3), 282-284 (2008).

32. Wiewiora M, Steplewska K, Piecuch JZ, Piecuch J. A rare case of primary gastric melanoma. Indian J. Surg. 82, 442-444 (2019).

33. Augustyn A, De Leon ED, Yopp AC. Primary gastric melanoma: case report of a rare malignancy. Rare Tumors 7(1), 5683 (2015).

34. Lagoudianakis EE, Genetzakis M, Tsekouras DK et al. Primary gastric melanoma: a case report. World J. Gastroenterol. 12(27), 4425-4427 (2006).

35. Liu Y, Xu YH, Xu J, Huang XY, Yuan H, Bian C. Primary gastric malignant melanoma: a case report. Zhonghua Zhong Liu Za Zhi 41(4), 293-294 (2019).

36. Eshtiaghpour D, Lee D, Reicher S, Datta A, Eysselein V. Primary gastric melanoma: wait, i thought the stomach did not have any melanocytes! Am. J. Gastroenterol. 109, S260 (2014).

37. Liang J, Yu S, Lee P, Chang K, Fang C. Endoscopic diagnosis of malignant melanoma in the gastric cardia: report of a case without a detectable primary lesion. Endoscopy (Stuttgart) 27(5), 409 (1995).

38. Slater JM, Ling TC, Slater JD, Yang GY. Palliative radiation therapy for primary gastric melanoma. J. Gastrointest. Oncol. 5(1), E22-E26 (2014).

39. Song W, Liu F, Wang S, Shi H, He W, He Y. Primary gastric malignant melanoma: challenge in preoperative diagnosis. Int. J. Clin. Exp. Pathol. 7(10), 6826-6831 (2014).

- Suggested the additional diagnostic criteria of 1-year survival postdiagnosis for diagnosis of primary gastric melanoma.

40. Phillips O, Higdon A, Colaco R, Fish H. Primary mucosal melanoma of the stomach. Case Rep. Gastrointest. Med. 2018, 6040693 (2018).

41. Cardoso C, Freire R, Gamito E, Quintana C, Cremers I, Oliveira AP. Esophageal melanocytosis. J. Port. Gastrenterol. 19(3), 158-159 (2012).

42. Kumari NS, Srujana S, Sireesha A, Krishna L, Kumar OS. Esophageal melanocytosis - an unusual melanocytic entity. J. Assoc. Physicians India 64(5), 75-76 (2016).

43. Omholt K, Grafström E, Kanter-Lewensohn L, Hansson J, Ragnarsson-Olding BK. KIT pathway alterations in mucosal melanomas of the vulva and other sites. Clin. Cancer Res. 17(12), 3933-3942 (2011).

44. Ohashi K, Kato Y, Kanno J, Kasuga T. Melanocytes and melanosis of the oesophagus in Japanese subjects—analysis of factors effecting their increase. Virchows Archiv. A 417(2), 137-143 (1990).

- Discussion regarding the presence of melanosis in the GI tract.

45. Kottschade LA, Grotz TE, Dronca RS et al. Rare presentations of primary melanoma and special populations: a systematic review. Am. J. Clin. Oncol. 37(6), 635-641 (2014).

46. Horowitz M, Nobrega MM. Primary anal melanoma associated with melanosis of the upper gastrointestinal tract. Endoscopy 30(7), 662-665 (1998).

47. Safaei A, Masood Tabib S, Farzaneh MR, Shahryari J, Bahmaniar M. Primary malignant melanoma of the gastrointestinal tract: report of two cases. Iranian J. Pathol. 9(3), 213-218 (2014).

48. Yde SS, Sjoegren P, Heje M, Stolle LB. Mucosal melanoma: a literature review. Curr. Oncol. Rep. 20(3), 28 (2018). 
49. Rabbie R, Ferguson P, Molina-Aguilar C, Adams DJ, Robles-Espinoza CD. Melanoma subtypes: genomic profiles, prognostic molecular markers and therapeutic possibilities. J. Pathol. 247(5), 539-551 (2019).

50. Sashiyama H, Takayama W, Miyazaki S et al. The diagnostic value of endoscopic ultrasonography and magnetic resonance imaging for anorectal malignant melanoma: report of a case. Surg. Today 33(3), 209-213 (2003).

51. Goel VK, Lazar AJ, Warneke CL, Redston MS, Haluska FG. Examination of mutations in BRAF, NRAS, and PTEN in primary cutaneous melanoma. J. Invest. Dermatol. 126(1), 154-160 (2006).

52. Spencer KR, Mehnert JM. Mucosal melanoma: epidemiology, biology and treatment. In: Melanoma. Springer, Cham, Switzerland, 295-320 (2016).

53. Malaguarnera G, Madeddu R, Catania VE et al. Anorectal mucosal melanoma. Oncotarget 9(9), 8785-8800 (2018).

54. Gallamini A, Zwarthoed C, Borra A. Positron emission tomography (PET) in oncology. Cancers (Basel) 6(4), 1821-1889 (2014).

55. Flaherty KT, Puzanov I, Kim KB et al. Inhibition of mutated, activated BRAF in metastatic melanoma. N. Engl. J. Med. 363(9), 809-819 (2010).

56. Beadling C, Jacobson-Dunlop E, Hodi FS et al. KIT gene mutations and copy number in melanoma subtypes. Clin. Cancer Res. 14(21), 6821-6828 (2008).

57. Kotteas E, Adamopoulos A, Drogitis $\mathrm{P}$ et al. Gastrointestinal bleeding as initial presentation of melanoma of unknown primary origin: report of a case and review of the literature. In Vivo 23(3), 487-489 (2009).

58. Wong CW, Fan YS, Chan TL et al. BRAF and NRAS mutations are uncommon in melanomas arising in diverse internal organs. J. Clin. Pathol. 58(6), 640-644 (2005).

59. Ordonez NG. Value of SOX10 immunostaining in tumor diagnosis. Adv. Anat. Pathol. 20(4), 275-283 (2013).

60. Si L, Wang X, Guo J. Genotyping of mucosal melanoma. Chin. Clin. Oncol. 3(3), 34 (2014).

61. Chudnovsky Y, Khavari PA, Adams AE. Melanoma genetics and the development of rational therapeutics. J. Clin. Invest. 115(4), 813-824 (2005).

62. Sivak M. The value of endoscopic ultrasonography in primary malignant melanoma of the esophagus. Gastrointest. Endosc. 46, 88-89 (1997).

63. Ao W, Wang J, Mao G et al. Primary hepatic melanoma: a case report of computed tomography and magnetic resonance imaging findings. Medicine (Baltimore) 98(25), e16165 (2019).

64. Schoder H, Larson SM, Yeung HW. PET/CT in oncology: integration into clinical management of lymphoma, melanoma, and gastrointestinal malignancies. J. Nucl. Med. 45(Suppl. 1), S72-S81 (2004).

65. Niknam R, Saberifiroozi M, Mahmoudi L, Forouhesh Tehrani Z. Diffuse melanoma of the stomach and duodenum: a case report. Middle East J. Dig. Dis. 3(2), 131-133 (2011).

66. Merkel EA, Gerami P. Malignant melanoma of sun-protected sites: a review of clinical, histological, and molecular features. Lab. Invest. 97(6), 630-635 (2017).

\section{- Examines possible genetic pathway for gastric melanoma.}

67. Curtin JA, Fridlyand J, Kageshita T et al. Distinct sets of genetic alterations in melanoma. N. Engl. J. Med. 353(20), 2135-2147 (2005).

68. Yonal O, Ibrisim D, Songur Y et al. Primary malignant melanoma of the esophagus. Case Rep. Gastroenterol. 7(2), 272-276 (2013).

69. Antonini F, Acito L, Sisti S, Angelelli L, Macarri G. Metastatic melanoma of the gallbladder diagnosed by EUS-guided FNA. Gastrointest. Endosc. 84(6), 1072-1073 (2016).

70. Kawakami H, Kubota Y. Malignant melanoma metastatic to the gallbladder diagnosed by endoscopic ultrasonography-guided fine-needle aspiration. Endosc. Ultrasound 6(6), 414-414 (2017).

71. Blecker D, Abraham S, Furth EE, Kochman ML. Melanoma in the gastrointestinal tract. Am. J. Gastroenterol. 94(12), 3427-3433 (1999).

\section{- $\quad$ First proposed definition of gastric melanoma.}

72. Danielsen M, Kjaer A, Wu M et al. Prediction of positron emission tomography/computed tomography (PET/CT) positivity in patients with high-risk primary melanoma. Am. J. Nucl. Med. Mol. Imaging 6(5), 277-285 (2016).

73. Krengli M, Masini L, Kaanders JH et al. Radiotherapy in the treatment of mucosal melanoma of the upper aerodigestive tract: analysis of 74 cases. A Rare Cancer Network study. Int. J. Radiat. Oncol. Biol. Phys. 65(3), 751-759 (2006).

74. Lian B, Si L, Cui C et al. Phase II randomized trial comparing high-dose IFN- $\alpha 2 b$ with temozolomide plus cisplatin as systemic adjuvant therapy for resected mucosal melanoma. Clin. Cancer Res. 19(16), 4488-4498 (2013).

75. Yang AS, Chapman PB. The history and future of chemotherapy for melanoma. Hematol. Oncol. Clin. North Am. 23(3), 583-597 (2009).

76. Yi JH, Yi SY, Lee HR et al. Dacarbazine-based chemotherapy as first-line treatment in noncutaneous metastatic melanoma: multicenter, retrospective analysis in Asia. Melanoma Res. 21(3), 223-227 (2011).

77. Chapman PB, Einhorn LH, Meyers ML et al. Phase III multicenter randomized trial of the Dartmouth regimen versus dacarbazine in patients with metastatic melanoma. J. Clin. Oncol. 17(9), 2745-2745 (1999). 
78. Bajetta E, Di Leo A, Zampino MG et al. Multicenter randomized trial of dacarbazine alone or in combination with two different doses and schedules of interferon alfa-2a in the treatment of advanced melanoma. J. Clin. Oncol. 12(4), 806-811 (1994).

79. Robert C, Karaszewska B, Schachter J et al. Improved overall survival in melanoma with combined dabrafenib and trametinib. N. Engl. J. Med. 72(1), 30-39 (2015).

80. Carvajal RD, Antonescu CR, Wolchok JD et al. KIT as a therapeutic target in metastatic melanoma. JAMA 305(22), 2327-2334 (2011).

81. Buzaid A. Cisplatin, vinblastine and dacarbazine alone in metastatic melanoma: preliminary results of a Phase III Cancer Community Oncology Program (CCOP) trial. Proc. Am. Soc. Clin. Oncol. 12, 389a (1993).

82. Guo J, Si L, Kong Y et al. Phase II, open-label, single-arm trial of imatinib mesylate in patients with metastatic melanoma harboring c-Kit mutation or amplification. J. Clin. Oncol. 29(21), 2904-2909 (2011).

83. Shoushtari AN, Munhoz RR, Kuk D et al. The efficacy of anti-PD-1 agents in acral and mucosal melanoma. Cancer 122(21), 3354-3362 (2016).

84. D'angelo SP, Larkin J, Sosman JA et al. Efficacy and safety of nivolumab alone or in combination with ipilimumab in patients with mucosal melanoma: a pooled analysis. J. Clin. Oncol. 35(2), 226-235 (2017).

85. Robert C, Thomas L, Bondarenko I et al. Ipilimumab plus dacarbazine for previously untreated metastatic melanoma. N. Engl. J. Med. 364(26), 2517-2526 (2011).

86. Larkin J, Chiarion-Sileni V, Gonzalez R et al. Combined nivolumab and ipilimumab or monotherapy in untreated melanoma. N. Engl. J. Med. 373(1), 23-34 (2015).

87. Satelli A, Li S. Vimentin in cancer and its potential as a molecular target for cancer therapy. Cell. Mol. Life Sci. 68(18), 3033-3046 (2011). 